\title{
A Case-Study Survey of an Eight-year Cluster of Motor Neurone Disease (MND) Referrals in a Rural English Village: Exploring Possible Aetiological Influences in a Hypothesis Stimulating Study
}

\section{Colin Pritchard ${ }^{1 *}$ and Anne Silk}

${ }^{1}$ Professor, School of Health \& Social Care, Bournemouth University, UK

${ }^{2}$ National Institute of Health Research, Dendron \& Neurodegenerative Diseases Network, Oxford, UK

\begin{abstract}
Objective: To test whether the Village incidence of new cases of Motor Neurone Disease (MND) over an 8-year period, is significantly different from those in the County to serve as a pilot study to identify possible interactive multienvironmental aetiology.

Design: Between September 2003-June 2011, Village MND cases were compared with the County's in people aged $>54$ years. The incidence of MND was determined and Odds ratios calculated. The Village MND mortality rates were juxtaposed against England \& Wales MND deaths over the period.

Setting: A rural Village flanked by Electro-Magnetic-Fields (EMF) close to an active airfield. The Village population has remained relatively stable, plane-take off from the airfield is at a low angle for 3-4 miles, with radar TACAN beams pulsed every 4 seconds.

Participants: General population (>54 yrs) in Village and County.

Main outcome measures: Cases and deaths of MND.

Results: Of the County's 236 MND cases, 11 came from the Village, equal to 1 MND case per 410 people, County rate was $1: 1,844$, yielding an Odds ratio of $4.5: 1$. Village MND deaths compared to England \& Wales gave an Odds ratio of 2.3: 1; England \& Wales MND deaths were double the County's.

Conclusion: The disproportionate incidence of Village MND, with its relatively intensive exposure to EMF and petrochemicals, leads us to a speculative hypothesis of possible multi-interactive environmental influences. Despite limitations inherent in cluster studies, these indicative results suggest that a more detailed national study of geographic, occupational, life-style and family background is merited and feasible.
\end{abstract}

Keywords: Motor neurone disease cases; Deaths; Cluster-study

\section{Introduction}

There is substantial evidence that neurological morbidity and mortality is increasing in most of the ten major Western countries and not simply age-related [1-4]. In particular there have been increases in Motor Neurone Disease (MND) rates in a number of Western countries over a relatively short time period [1-6]. Some argue these rises may be due to more accurate diagnosis [7]. Whilst there may be some truth in this, it can hardly account for the major rises reported in England \& Wales, between 1980 and 2010, up 56\% in males and 65\% in females and in terms of UK non- Alzheimer Nervous Diseases deaths, these have risen $85 \%$ in the under 74 year old men and $71 \%$ in women, with substantial rises in 16 of the 20 Western countries [4].

One argument to account for these increase in the incidence of neurological morbidity and mortality is the Gompertzian longevity hypothesis, that is, as longevity increases people are now living longer to develop aged-related diseases they had previously would not have lived long enough to develop [8]. However, longevity has hardly increased so substantially over the last 30 years (1980-2010) to account for the extent the global neurological changes, nor do various studies explain increases in diseases such as breast cancer; nor explain earlier brain tumours and a continued rise in cancer incidence in the under 50 year olds, nor explain the differences in neurological deaths by gender in and between different countries. Crucially, the Gompertzian hypothesis does not explain the relatively new phenomena of earlyonset dementia', or earlier cases ( $<50$ years) of MND [9-11]. These changes are reflected in a need for a 'Young Parkinson's Support
Group', with the British Parkinson's Society, and a new charity, Young Dementia UK, and the established of the early onset dementia' category, such developments would have been unthinkable 30 or more years ago.

Reviews on the aetiology of MND show a growing epigenetic consensus $[2-6,11,12,13]$, although some are familial, carrying a genetic predisposition, whilst Sporadic cases of MND have a multi-factorial aetiology [14-16] such as heavy metals, contact sports, pesticides, agroneurotoxic chemicals ranging across occupations, and exposure to low levels of organophosphates [10-17] but not all studies have been consistent $[7,18,19]$. Recently however, there are complex links with Electro-Magnetic-Field' (EMF) in both human and animal studies, through rises in EMF backgrounds e.g. computers, mobile phones and domestic appliances, all suggesting an interaction of various environmental 'triggers' 13, [18-28]. Indeed it has long been recognised

*Corresponding author: Colin Pritchard, Professor, School of Health \& Social Care, Bournemouth University, UK, Tel: 02380766487; E-mail: CPritchard@bournemouth.ac.uk

Received January 06, 2014; Accepted February 03, 2014; Published February 06, 2014

Citation: Pritchard C, Silk A (2014) A Case-Study Survey of an Eight-year Cluster of Motor Neurone Disease (MND) Referrals in a Rural English Village: Exploring Possible Aetiological Influences in a Hypothesis Stimulating Study. J Neurol Disord 2: 147. doi:10.4172/2329-6895.1000147

Copyright: (c) 2014 Pritchard C, et al. This is an open-access article distributed under the terms of the Creative Commons Attribution License, which permits unrestricted use, distribution, and reproduction in any medium, provided the original author and source are credited. 
that "in contrast to an electric field a magnetic field is more penetrating and very difficult to shield. It easily penetrates humans and in the case of an alternating or rotating field induces circulating currents" [25], whilst one systematic review concluded as measuring techniques have become more sensitive "weak EMF can control and amplify biological processes through their effect on charge distribution" [13] thus despite the controversy surrounding the issue, not least the problem of accurate measuring, these research studies, with more technically sophisticated technology are indicating potential damage to humans [9-27].

It would seem that people exposed to the same environmental phenomena may develop different disorders, the neurological or malignant in particular, dependent upon any underlying genetic predisposition $[4,5,12-15]$. Some MND research has centred upon geographic 'clusters' ranging from a concentration of familial MND people to the proximity to various environmental 'triggers' $[5,10,16,17,20]$. British cluster studies are relatively rare though a recent study linked the aetiology of MND to density of population [6], as with greater economic activity comes more environmental triggers. Interestingly an inner London study found no significant differences between MND patients of African and European ancestry MND patients, which was unexpected as higher incidence is usually found amongst White compared to Black people, which perhaps points towards an over-arching influence of shared environmental factors [29]? However, the problem remains that no underlying mechanism has been identified to facilitate the development of effective treatments and equally important possible prevention.

Despite the inevitable limitations of cluster research, we took the opportunity for a hypothesis stimulating study of a local audit that could serve as a pilot study for a larger national initiative, by examining a decade of MND cases in a well-defined population in a village in an area of $4 \mathrm{~km}^{2}$, with a population of 4,150 people over the age of 54 . The possible significant interactive environmental triggers are major sources of non-ionising EMF exposure from communication signals and close proximity to a very active airfield, with its relative high rate of petrochemical exposure, to determine whether there is any indicative evidence of disproportionate incidence in The Village, compared to the rest of the County.

There is one working null hypothesis:-.

That over an eight year period there will be no statistically significant differences in the numbers of newly reported MND cases in the Village and the County.

\section{Methodology}

One immediate problem is what is the incidence of MND? A detailed UK case study on a 3 million GP data base concluded the average for both sexes was 3.25 per 100,000, based upon 830 new cases over a 15 years period [2]. This would yield one case from 30,769 people. However, another British estimate based nationally argued for between 5-7 people per 100,000, which would be one in 16,666 [30], which might account for the claim that GP's may only see 2 or 3 cases in their careers [31], the relative rarity therefore of such small numbers of cases should be borne in mind when discussing the results.

Less than 4\% of the total 1,941 MND deaths in England \& Wales were under 50 years old [4] so considering the incidence of MND the focus of the analysis will be upon people aged $>54$ years, the age of the youngest patient from the village, to determine the known deaths from of MND in the Village and County, an age band 55-64 years which is identified in national morbidity and mortality studies, so age-related data on deaths can uniformly be extracted from County and England \& Wales data [4]. The numbers of new cases of MND and deaths of people aged $>54$ years, collected quarterly through the local MND Association, and forwarded to the national body, were extrapolated for an English Village and County audit. It was not possible to undertake a study that involved the patients so detailed knowledge of their backgrounds and family history was unavailable so total confidentiality and anonymity is preserved for both patients, village and county.

All patients had been treated at a major neurological centre in the local city hospital; however we did not have access to death certificates.

Geographical features are important as The Village is $2.5 \mathrm{kms}$ from major communications sources of EMF (Non-ionising radiation), laying South West, which is the prevailing wind, of a busy airport. Planes have a low-angle take off for 3-4 miles before steeper ascent and therefore aerosol particulates might well be of significance [19,2428 ], and there are radio masts on the two downs either side of the village. Moreover, radar beams with TACAN rotate, which are pulsed every 4 seconds at a very low angle to the ground, with strong pulsed microwave narrow beam, square waves not sinusoidal.

There was no significant change in population of the Village, especially amongst people $>54$ years, nor was there any health unit that might have attracted patients to the area. To ensure strictest confidentiality both Village and County remain anonymous.

The relatively small population of County and Village does not pose a problem for statistical analysis, because as the focus concerns a relatively uncommon disorder, the size of the population becomes a relative strength, as any significant numbers emerging suggests the results are more likely to be due to possible interactive environmental influence rather than a statistical artefact.

The comparative data are new MND cases known to the County MND Association over an eight-year period between September 2003 and June 2011 to match the latest confirmed national MND data. It is possible that the County association did not know of all cases, although the Association was informed about new patients by the regional centre as it was recognised just how valuable was the support the Association provided. Our clinical and practice experience suggests that very few people with MND do not eventually make some contact with the Association but it is possible that there were missing cases from the village and county over the period.

A limitation in analysing MND clusters is the question of whether place of birth or length of stay in a particular area residence is most important feature in terms of exposure to any negative 'triggers', or, might the clusters be linked to a genetic concentration within the population $[4,11,12,17]$. As both Village and County are relatively rural, it would be expected that there would be similar levels of exposure to organo-phosphates associated with agro-chemicals [22]. However, it was not possible to gain detailed clinical information on the individuals either in regard to family medical history or current or previous occupations.

Population data of the village and of the rest of the county by age and gender was extracted from the Council 2010 census data. Male and female cases will be summed together to give the total of new MND cases. This enables us to calculate a ratio of the incidence of MND cases per the two populations and use a chi square test to compare the two groups. As will be seen, the time span and populations are big enough to merit an analysis of relatively rare events, such as MND.

To place County and Village cases in context, they are juxtaposed 
against the latest current MND mortality rates of the combined gender MND death rates per million (pm) in England \& Wales of people aged $>54$ years [5]. Ratios of MND cases to population are calculated for Village, County from which Odds ratios are calculated, and in relation to MND mortality between the Village and England \& Wales data [4].

The numbers of annual average of deaths over the period for The Village, the County and England \& Wales are translated into rates per million (pm) of population to compare with national rates.

\section{Findings}

\section{Population}

In 2010 there were 4,510 people aged $>54$ years in The Village and 414,920 people in the rest of The County. In the same year there were 17, 426,070 men and women aged $>54$ years in the rest of England \& Wales.

\section{MND cases 2003-2011}

Over the eight-year period there were 11 MND cases in The Village and a further 225 in the rest of the County seen in Table 1.

A ratio of MND cases to population in The Village was 1: 410 compared to 1: 1,844 for the rest of the County an Odds ratio of 4.5: 1 thus The Village had more than four times the rate of MND cases than the rest of the County. Chi square test showed this was significant $\left(\mathrm{X}^{2}=28.54 \mathrm{p}<0.001\right)$.

We have no official MND mortality figures for the County but a cautious estimate of the numbers of annual deaths over the period, based upon the local MND association information, would be $57 \mathrm{pm}$ compared to the village, $222 \mathrm{pm}$ an Odds ratio of 4.04: 1.

\section{England \& wales as context}

Placing the above results in a national context an examination of MND deaths of people $>54$ years in England \& Wales between 2003 and 2010 produced an interesting finding shown in Table 2. In 2003 there were 1,409 MND deaths in England \& Wales, a ratio per population of 1: 12,634 but by 2010 there were 1,867 MND deaths in England \& Wales a ratio of 1: 9558, a 25\% increase over the period, rising from $79 \mathrm{pm}$ to $105 \mathrm{pm}$, which is statistically significant $\left(\mathrm{X}^{2}=62.90\right.$ $1 \mathrm{~d} / \mathrm{f} \mathrm{p}<0.001)$.

\begin{tabular}{|l|l|l|l|l|}
\hline $\begin{array}{l}\text { Population County \& } \\
\text { Village }\end{array}$ & $\begin{array}{l}\text { Total } \\
\text { Population } \\
\text { >54 yrs }\end{array}$ & $\begin{array}{l}\text { MND Cases } \\
\text { pa }\end{array}$ & $\begin{array}{l}\text { MND } \\
\text { Deaths } \\
\text { pa }\end{array}$ & $\begin{array}{l}\text { Ratios } \\
\text { Population: } \\
\text { MND }\end{array}$ \\
\hline $\begin{array}{l}\text { Total County 2003-11 } \\
\text { MND p.m. p.a. }\end{array}$ & 419,430 & 236 & 24 & $1: 1,777$ \\
\hline $\begin{array}{l}\text { The Village' 2003-2010 } \\
\text { MND Cases p.m. p'a }\end{array}$ & 4,510 & 70 pm & 57 pm & $1: 17,476$ \\
\hline $\begin{array}{l}\text { The County-minus } \\
\text { 'Village' }\end{array}$ & 414,920 & 305 pm & 1 & $1: 410$ \\
MND Cases p.m. p.a. & 225 & 23 & $1: 4,510$ \\
\hline
\end{tabular}

Table 1: Population aged 54years+ \& MND cases 2003-2011 numbers and rates per million (pm).

\begin{tabular}{|l|l|l|l|l|}
\hline $\begin{array}{l}\text { England \& Wales } \\
\text { Years }\end{array}$ & $\begin{array}{l}\text { Population } \\
\mathbf{> 5 4} \text { yrs }\end{array}$ & $\begin{array}{l}\text { MND } \\
\text { Deaths }\end{array}$ & Ratios & Deaths pm pa. \\
\hline England \& Wales 2003 & $17,801,149$ & 1,409 & $1: 12,634$ & $79 \mathrm{pm}$ \\
\hline England \& Wales 2010 & $17,845,500$ & 1,867 & $1: 9,558$ & $105 \mathrm{pm}$ \\
\hline The Village & 4,150 & 1 & $1: 4,150$ & $222 \mathrm{pm}$ \\
\hline
\end{tabular}

Table 2: MND deaths in people >54years in England \& Wales in 2003 and 2010 numbers and rates per million (pm).
It is very noteworthy, that whilst the national rate was nearly double that of the rural County rate $(55 \mathrm{pm})$ the 'Village' MND mortality rate of $222 \mathrm{pm}$ was double that of the latest England \& Wales rate.

The Odds ratios between The Village deaths and England \& Wales MND mortality gave an Odds ratio of 2.1: 1 .

\section{Study limitations}

We share the perennial limitations of cluster studies in that we lacked detailed information on the length of residence in the index geographical area, place of birth and detailed occupational information over time, or any knowledge of family medical history, especially in relation to neurological or malignant disease because patients were not directly involved, which is a real limitation and means these results can only be indicative of possible interactive environmental influences upon the incidence of MND.

There is evidence from a patient-centred study that focused upon patient agendas, gives us confidence that these problems could be easily over-come if a study involved MND patients from a national sample, as they who would be likely to want to contribute the data inherent in their situations [32]. However, these limitations were to a degree off-set by having a well defined population of the comparative groups, the exceptional nature of the close proximity of two sources of possible 'toxic/trauma' triggers/exposure and the length of time the review covers. Furthermore, the study is given a degree of external validation in that the increases in the County cases matches the similar increase found in England \& Wales MND mortality over the period, remembering that the County MND rate was almost half the national rate [4]. Moreover, bearing in mind recent UK results on the incidence of MND [2,30,31] where the incidence rate was estimated at between one in 16,666 to 30,769 [2,31], whilst this sample had a ratio of 1 : 410 , indicates that there would be merit in further research exploring possible clusters in relation to population centres that have both above average EMF exposure and an airfield proximity, with its raised nonionising and petrochemical exposure [13,18,19,21-28] as there is evidence of occupational links [22,23], with MND, including airline pilots who have a particular exposure [22], although there continues to be a degree of uncertainty with specific occupations and links to different neurological disorders, $[7,23,24]$. However it is acknowledged that a recent meta-analysis on the link between electro-magnetic-field exposure and occupation and MND only cautiously suggested there might be a link [19]. Clearly more integrated research is required to better understand the possible interactive multiple factors that might contribute to the development of MND.

\section{Discussion}

We can cautiously reject the null hypothesis that there would be no differences in the proportions of new MND cases in The Village and the rest of The County.

Despite small numbers, when placing this local study in a national context, it should be remembered that between 1980-2010 British MND deaths rose for men and women by $56 \%$ and $65 \%$ and in regards to the UK non-Alzheimer's Nervous Disease deaths in the UK rose $85 \%$ for men and $71 \%$ for women over the same period [4]. Clearly there is a need for greater understanding of what has contributed to these changing national rates of neurological morbidity and mortality, with similar rises being been found in 16 of the 20 Western countries between 1980-2010 [4].

The question is what might explain The Village and the County findings? 
The answer is frankly the numbers are too small but paradoxically, as MND is a relatively uncommon disease, the disproportionate number found in the Village, suggest the results are more than just a possible artefact. Thus we can only speculate as to possible interactive influences, although we generally favour an epigenetic explanation of neurological and malignant disorders $[4,6,9,16,20,23,24-28,33]$, which is increasingly supported by larger recent epidemiological studies $[2-4,6]$. Indeed in a major longitudinal study of the age of onset of 'normal' cognitive decline over a 20 years period, they reported it appears to be starting earlier than initially estimated [34], however this might well be explained as the beginning of softer symptoms of earlier neurological disease, and picking up early signs of the recent confirmed rise in earlier onset neurological mortality $[1,4,10]$, especially when considering growing evidence of impact of low-level organophosphates and exposure to non-ionising EMF [18-28,33]. In view of only a possible slight link between EMF and the development of MND [19], might it be that being in a rural area, with higher levels of background agrochemicals, the additional factor of proximity to the airfield, with its concentration of petrochemicals and the local geography, enhanced any vulnerability of people in the area, with possible genetic vulnerability?

Although, we have to be very cautious as we can only speculate upon possible interactive causes, this project should be seen as a pilot study to justify a national study of new MND patients as we appear to have identified a geographic hotspot that where theoretically people are disproportionately exposed to a range of possible triggers within the environment. If an active partnership could be established between people with newly diagnosed MND and a research term, working at a national level with the MND Association, it would likely get a very high response rate, to create a powerful data set.

If this 'double' exposure possibly contributes to these disproportionate rates of $M N D$, this could only be really tested in a national study. This ideally would be with new MND patients, designed with all due safeguards to ensure free consent, full and total anonymity and confidentiality, to test whether other hot spots might be identified that would contribute to a better understanding of the multi-epigenetic factors associated with the aetiology of motor neurone disease. This would add to the further understanding of MND, possibly identifying priority areas for research, with potential preventive opportunities, which a national geo-socio-economic-familial questionnaire study could deliver.

\section{References}

1. Day TG, Scott M, Perring R, Doyle $P$ (2007) Motor neuron disease mortality in Great Britain continues to rise: examination of mortality rates 1975-2004. Amyotroph Lateral Scler 8: 337-342.

2. Alonso A, Logroscino G, Jick SS, Hernán MA (2009) Incidence and lifetime risk of motor neuron disease in the United Kingdom: a population-based study. Eur J Neurol 16: 745-751.

3. Fang F, Valdimarsdóttir U, Bellocco R, Ronnevi LO, Sparén P, et al. (2009) Amyotrophic lateral sclerosis in Sweden, 1991-2005. Arch Neurol 66: 515-519.

4. Pritchard C, Mayers A, Baldwin D (2013) Changing patterns of neurological mortality in the 10 major developed countries--1979-2010. Public Health 127 357-368.

5. Forbes RB, Colville S, Parratt J, Swingler RJ (2007) The incidence of motor nueron disease in Scotland. J Neurol 254: 866-869.

6. Scott KM, Abhinav K, Wijesekera L, Ganesalingam J, Goldstein LH, et al. (2010) The association between ALS and population density: A population based study. Amyotroph Lateral Scler 11: 435-438.

7. Goldacre MJ, Duncan M, Griffith M, Turner MR (2010) Trends in death certification for multiple sclerosis, motor neuron disease, Parkinson's disease and epilepsy in English populations 1979-2006. J Neurol 257: 706-715.
8. Riggs JE, Schochet SS Jr (1992) Rising mortality due to Parkinson's disease and amyotrophic lateral sclerosis: a manifestation of the competitive nature of human mortality. J Clin Epidemiol 45: 1007-1012.

9. Pritchard C, Hickish T (2011) Comparing cancer mortality and GDP health expenditure in England and Wales with other major developed countries from 1979 to 2006. Br J Cancer 105: 1788-1794.

10. Sabatelli M, Madia F, Conte A, Luigetti M, Zollino M, et al. (2008) Natura history of young-adult amyotrophic lateral sclerosis. Neurology 71: 876-881.

11. Imam I, Ball S, Wright D, Hanemann CO, Zajicek J (2010) The epidemiology of motor neurone disease in two counties in the southwest of England. J Neurol 257: $977-981$

12. Lunke S, El-Osta A (2009) The emerging role of epigenetic modifications and chromatin remodeling in spinal muscular atrophy. J Neurochem 109: 15571569 .

13. Blank M (2008) Protein and DNA reactions stimulated by electromagnetic fields. Electromagn Biol Med 27: 3-23.

14. Al-Chalabi A, Lewis CM (2011) Modelling the effects of penetrance and family size on rates of sporadic and familial disease. Hum Hered 71: 281-288.

15. Graham AJ, Macdonald AM, Hawkes CH (1997) British motor neuron disease twin study. J Neurol Neurosurg Psychiatry 62: 562-569.

16. Bastos AF, Orsini M, Machado D, Mello MP, Nader S, et al. (2011) Amyotrophic lateral sclerosis: one or multiple causes? Neurollnt 3: e4.

17. Callaghan B, Feldman D, Gruis K, Feldman E (2011) The association of exposure to lead, mercury and selenium and the development of amyotrophic lateral sclerosis and the epigenetic implications. Neurodegener Dis 8: 1-8.

18. Parlett LE, Bowman JD, van Wijngaarden E (2011) Evaluation of occupational exposure to magnetic fields and motor neuron disease mortality in a population-based cohort. J Occup Environ Med 53: 1447-1451.

19. Zhou H, Chen G, Chen C, Yu Y, Xu Z (2012) Association between extremely low-frequency electromagnetic fields occupations and amyotrophic lateral sclerosis: a meta-analysis. PLoS One 7: e48354.

20. Diekstra FP, Beleza-Meireles A, Leigh NP, Shaw CE, Al-Chalabi A (2009) Interaction between PON1 and population density in amyotrophic lateral sclerosis. Neuroreport 20: 186-190.

21. Ross SM, McManus IC, Harrison V, Mason O (2013) Neurobehavioral problems following low-level exposure to organophosphate pesticides: a systematic and meta-analytic review. Crit Rev Toxicol 43: 21-44.

22. Nicholas JS, Butler GC, Lackland DT, Tessier GS, Mohr LC Jr, et al. (2001) Health among commercial airline pilots. Aviat Space Environ Med 72: 821 826.

23. Sutedja NA, Fischer $\mathrm{K}$, Veldink $\mathrm{JH}$, van der Heijden GJ, Kromhout $\mathrm{H}$, et al. (2009) What we truly know about occupation as a risk factor for ALS: a critical and systematic review. Amyotroph Lateral Scler 10: 295-301.

24. Johnansen C (2004) Electromagnetic fields and health effects - epidemiologica studies of cancer, diseases of the central nervous system and arrhythmiarelated heart disease. Scand J Work Environ Health. Supplement 1: 1-80

25. Halgamuge MN (2013) Pineal melatonin level disruption in humans due to electromagnetic fields and ICNIRP limits. Radiat Prot Dosimetry 154: 405-416.

26. Begum N, Wang B, Mori M, Vares G (2012) Does ionizing radiation influence Alzheimer's disease risk? J Radiat Res 53: 815-822.

27. Grigor'evluG (2012) [lonizing and non-ionizing radiation (comparative risk estimations)]. Radiats Biol Radioecol 52: 215-218

28. Christ A, Guldimann R, Bühlmann B, Zefferer M, Bakker JF, et al. (2012) Exposure of the human body to professional and domestic induction cooktops compared to the basic restrictions. Bioelectromagnetics 33: 695-705.

29. Rojas-Garcia R, Scott KM, Roche JC, Scotton W, Al-Chalabi A, et al. (2012) No evidence of a large difference in ALS frequency in populations of African and European origin. A population based study in inner city London. Amyotroph Lateral Scler 13: 66-68.

30. PatientPlus (2013) Motor Neurone Disease: Epidemiology

31. McDermott CJ, Shaw PJ (2008) Diagnosis and management of motor neurone disease. BMJ 336: 658-662.

32. Pritchard C, Lindsay K, Cox M, Foulkes L (2011) Re-evaluating the Nationa 
Citation: Pritchard C, SilkA (2014) A Case-Study Survey of an Eight-year Cluster of Motor Neurone Disease (MND) Referrals in a Rural English Village: Exploring Possible Aetiological Influences in a Hypothesis Stimulating Study. J Neurol Disord 2: 147. doi:10.4172/2329-6895.1000147

Page 5 of 5

Subarachnoid Haemorrhage study (2006) from a patient-related-OutcomeMeasure perspective: comparing fiscal outcomes of Treatment-as-Usual with an enhanced service. British Journal of Neurosurgery 25: 376-83.

33. Caller TA, Field NC, Chipman JW, Shi X, Harris BT, et al. (2012) Spatial clustering of amyotrophic lateral sclerosis and the potential role of BMAA Amyotroph Lateral Scler 13: 25-32.

34. Singh-Manoux A, Kivimaki M, Glymour MM, Elbaz A, Berr C, et al. (2012) Timing of onset of cognitive decline: results from Whitehall II prospective cohort study. BMJ 344: d7622. 